\title{
Gambaran Penilaian Status Malnutrisi dan Lama Rawat Inap Pasien Hipertensi di RSUD Ir. Soekarno Sukoharjo
}

\author{
Andi Kurniawan ${ }^{1}$, Rusjiyanto ${ }^{2}$ \\ ${ }^{1}$ Mahasiswa Program Studi Ilmu Gizi Fakultas Ilmu Kesehatan Universitas Muhammadiyah \\ Surakarta. Email: andikurniawansolo@gmail.com \\ ${ }^{2}$ Kepala Bidang Pelayanan Penunjang RSUD Ir. Soekarno Sukoharjo
}

\begin{abstract}
Hypertension disease in Indonesia are increasing every year. Manifestation of hypertension's symptom can affect to malnutrition status and indirectly affect to length of stay. The objective of this research to know the overviews of malnutrition and length of malnutrition and length of stay of hypertension patient at RSUD Ir. Soekarno, Sukoharjo

The research description research with observational approach andcross sectional study design. The sampling techniqueused is consecutive sampling as much as 24 respondents. The assessment of malnutrition using Subjective Global Assessment, while the patient's length of stay is obtained by calculating the difference between date of attendance and date of left the hospital.

Respondent with female gender is 58,9\%. Most respondents are middle age (50\%). Level of education elementary school is $41 \%$ respondents. The job of respondents $41 \%$ are labor. Respondent with hypertension stage 2 with length of stay are 52\%. Hypertension stage 2 respondent with length of stay that classified medium as much as 52\%. Respondent's nutritional status that classified as bad nutrition 10,5\% and poor nutrition 21,2\%. The majority of SGA score of patients is A or not malnutrition.
\end{abstract}

Keywords : Hypertension, Malnutrition, Length of Stay

PENDAHULUAN

Penyakit hipertensi merupakan hidupnya (Sianaga, 2013; Sulistyarini, 2013). Pada umumnya penyakit ini sering menyerang usia lansia (>45 tahun) (Desinta, 2016). Penyakit hipertensi dapat dimulai pada usia 40 tahun dan semakin beresiko pada usia 60 tahun (Fitria, 2016; Ekawati dan Afridah, 2015).

Dua penelitian ditempat berbeda sakit dalam kesehariannya sering merasakan keluhan pusing, anggota badan lemas, dan jantung berdebar, sehingga sering menghambat aktivitas maupun kualitas menyebutkan prevalensi hipertensi di salah satu rumah sakit di Yunani adalah $89 \%$ dari 137 pasien yang menjadi responden 
(Triantafyllou et al., 2010), sedangkan di salah satu daerah di Kanada sebesar 23,1\% dari 1.706 jumlah responden (Blais et al., 2014). Pada tahun tahun 2007 prevalensi hipertensi di Indonesia sebanyak 31,7\%, namun terjadi penurunan pada tahun 2013 menjadi 26\%. Data ini tidak jauh berbeda dengan prevalensi hipertensi di Jawa Tengah yaitu 26,4\% (Kementrian Kesehatan, 2013). Sedangkan kasus hipertensi di seluruh rumah sakit Kabupaten Sukoharjo sebanyak 1.872 diagnosa (Dinas Kesehatan Sukoharjo, 2014). Penyakit hipertensi berdasarkan survey pendahuluan di rumah sakit umum daerah (RSUD) Sukoharjo masuk kedalam peringkat 10 besar penyakit. Pada tahun tersebut terdapat 281 kasus penyakit hipertensi primer dengan rerata lama hari perawatan (AVLOS) cukup tinggi yaitu 4,2 hari dan dalam kondisi status gizi menurut IMT cukup baik yaitu 22,8.

Pasien rawat inap dengan diagnosa penyakit hipertensi dan disertai dengan komplikasi penyakit lain akan berakibat pada peningkatan lama hari perawatan yang cukup lama yaitu lebih dari tujuh hari perawatan (Peacock et al., 2011), dimana lama rawat inap berakibat langsung pada pembengkakan biaya yang akan dikeluarkan oleh pasien (Bambungan et al., 2017). Penelitian di
RSUD Sanglah tahun 2013 melaporkan $52,3 \%$ mengalami hipertensi primer dan mempunyai rata rata lama hari perawatan cukup panjang yaitu sebesar 7,5 hari (Sugiarta dan Satriyasa, 2014).

\section{METODE PENELITIAN}

Penelitian yang dilakukan adalah penelitian deskriptif dengan pendekatan observasional dan rancangan penelitian cross sectional. Penelitian ini menggunakan subjek pasien dengan diagnosa hipertensi dan menjalani perawatan di bangsal rawat inap Rumah Sakit Umum Daerah (RSUD) Ir. Soekarno Sukoharjo. Populasi penelitian ini yaitu semua pasien yang terdiagnosa penyakit hipertensi primer dan menjalani perawatan di instalasi rawat inap tahun pada tahun 2018 dan memenuhi beberapa kriteria inklusi maupun eksklusi.

Jumlah total sampel penelitian sebanyak 24 pasien. Perhitungan sampel ditentukan berdasarkan jumlah proporsi. Tehnik sampling yang digunakan adalah consecutive sampling.

Variabel bebas dalam penelitian ini adalah penilaian status malnutrisi sedangkan variabel terikat adalah lama rawat inap. Pengumpulan data status malnutrisi pasien menggunakan form Subjective global assessment (SGA). Data lama rawat inap 
pasien didapatkan dengan menghitung selisih antara tanggal masuk dengan tanggal keluar rumah sakit. Lama rawat inap dikategorikan menjadi pendek apabila pasien dirawat 1-3 hari, sedang (4-7 hari) dan panjang ( $\geq 7$ hari).

\section{HASIL DAN PEMBAHASAN}

\section{A. Karakteristik Umum Responden}

1. Jenis Kelamin, Umur, Pendidikan,

\section{Pekerjaan}

Terdapat dua faktor penyebab hipertensi yaitu Faktor yang dapat dirubah seperti gaya hidup dan konsumsi makanan. Sedangkan jenis kelamin dan umur merupakan penyebb hipertensi yang tidak dapat dirubah.

Tabel 1. Distribusi karakteristik umum responden berdasarkan jenis kelamin, umur, tingkat pendidikan, dan pekerjaan,

\begin{tabular}{lll}
\hline Jenis kelamin & $\begin{array}{c}\text { Frekuensi } \\
(\mathbf{n})\end{array}$ & $\begin{array}{c}\text { Presentase } \\
(\%)\end{array}$ \\
\hline Perempuan & 14 & 58,3 \\
Laki laki & 10 & 41,7 \\
Total & 24 & 100,0 \\
\hline Umur & & 50,0 \\
Usia Pertengahan & 12 & 33,3 \\
Lansia & 8 & 16,7 \\
Lansia Tua & 4 & 100,0 \\
Total & 24 & \\
\hline Pendidikan & & 20,8 \\
Tidak sekolah & 5 & 41,5 \\
SD & 10 & 12,5 \\
SLTP & 3 & 25,0 \\
SLTA & 6 & 100,0 \\
Total & 24 & \\
\hline Pekerjaan & & 20,8 \\
Tidak bekerja & 5 & 16,7 \\
Petani & 4 & 41,7 \\
Buruh & 10 & 20,8 \\
Pedagang & 5 & 100 \\
Total & 24 & \\
\hline
\end{tabular}

Berdasarkan tabel 1. Diketahui responden pada penelitian ini sebagian besar berjenis kelamin perempuan yaitu 58,3\% . Hasil penelitian ini mendukung penelitian yang dilakukan di RSUP Padang maupun di Uganda, berturut turut ditemukan bahwa penyakit hipertensi primer paling banyak diderita oleh perempuan 64,3\% (Sedayu et al., 2015) dan 59,8\% (Guatude et al., 2015). Hipertensi pada perempuan banyak dipengaruhi dari faktor hormonal yaitu hormon estrogen yang semakin berkurang saat memasuki masa menapouse. Hormon estrogen berfungsi untuk mengendalikan kadar LDL dan mengatur HDL pada pembuluh darah, selain itu perubahan hormonal estrogen yang semakin berkurang juga dapat memengaruhi kenaikan berat badan. Selain itu pembuluh darah semakin reaktif terhadap konsumsi natrium (Pakar Gizi Indonesia, 2017).

Berdasarkan tabel 1. Diketahui pasien hipertensi lebih banyak diderita pada kategori usia pertengahan atau middle age sebanyak 58,3\%. Hasil ini juga sejalan dengan penelitian lain bahwa penyakit hipertensi banyak diderita pada umur diatas 50 tahun (Agustina, 2014; Arifin, 2016). Penyakit hipertensi di Nepal juga akan meningkat seiring dengan pertambahan 
umur disemua populasi (Mehta dan Shrestha, 2018). Semakin tua usia seseorang akan terjadi perubahan elastisitas pada struktur pembuluh darah sehingga terjadi penyempitan dan kekakuan pada dinding pembuluh darah, juga semakin banyak tumpukan plak disekitar aliran darah dan akan beresiko menjadi ateroklerosis. Hal ini dapat memunculkan sifat vasokonstruksi pembuluh darah yang akan berujung pada penyakit hipertensi (Price dan Wilson, 2006).

Berdasarkan tabel 1 sebanyak $41 \%$ sampel berpendidikan rendah atau setingkat Sekolah Dasar. Penyakit hipertensi dapat terjadi karena kurangnya pengetahuan masyarat tentang bahaya dan cara penanggulangannya. Adanya hubungan kualitas pengetahuan terkait kesehatan menjadi penting untuk dapa merubah perilaku keseharian, hal ini merupakan hasil jangka menengah dari terselenggaranya pendidikan kesehatan di masyarat (Fitria dan Marissa, 2016). Namun tingkat pendidikan juga harus sejalan dengan mudahnya akses terhadap informasi kesehatan untuk menjalankan hidup sehat, karena penelitian lain mengatakan pendidikan tidak selamanya ikut berperan terhadap timbulnya penyakit hipertensi, selain diderita dari kalangan berpendidikan rendah hipertensi ternyata juga banyak diderita dari kalangan berpendidikan tinggi karena kurangnya informasi yang mereka dapat dari tenaga kesehatan (Ramdhani et al., 2013).

Berdasarkan tabel 1. Penderita hipertensi sebagian besar mempunyai pekerjaan sebagai buruh $(41,7 \%)$. Pekerjaan ini merupakan terbanyak karena daerah Kabupaten Sukoharjo merupakan salah satu wilayah yang terdapat beberapa perusahaan pabrik sehingga banyak masyarakat yang bekerja menjadi karyawan dipabrik tersebut. Seseorang dengan pekerjaan sebagai karyawan swasta cenderung dituntut untuk dapat memenuhi target perusahaan, jika hal ini berlangsung lama dapat memicu tekanan sikis maupun psikis dan akan berujung pada depresi atau stress. Pada kondisi seperti ini akan terjadi resistensi pembuluh darah perifer dan peningkatan vasokrontruksi karena adanya peningkatan produksi hormon adrenalin yang distimulus dari syaraf simpatis (Lita, 2017).
B. Distribusi Subjek Penelitian
Berdasarkan Stadium Hipertensi
Dengan Lama Rawat Inap 
Tabel 2. Distribusi subjek penelitian berdasarkan stadium hipertensi dengan lama hari perawatan

\begin{tabular}{lccccccc}
\hline \multirow{2}{*}{$\begin{array}{c}\text { Stadium } \\
\text { Hipertensi }\end{array}$} & \multicolumn{2}{c}{ Lama Rawat Inap } & \multicolumn{2}{c}{ Total } \\
\cline { 2 - 5 } & \multicolumn{2}{c}{ Pendek } & \multicolumn{2}{c}{ Sedang } & & \\
\hline Stage 1 & 3 & 60 & 2 & 40 & 5 & 100 \\
Stage 2 & 9 & 47 & 10 & 52,6 & 19 & 100 \\
\hline
\end{tabular}

Berdasarkan tabel 2. Pasien dengan stadium hipertensi stage 2 yang mengalami lama hari perawatan pendek sebanyak $47 \%$. Sedangkan pasien dengan stadium hipertensi stage 2 yang mengalami lama hari perawatan sedang sebanyak 52\%. Pada penelitian ini dapat diketahui bahwa stadium hipertensi dapat menjadi salah satu faktor pemicu pasien mendapatkan perawatan lebih tama. Penelitian di Semarang menyebutkan stage hipertensi yang semakin tinggi akan menyebabkan pasien mengalami masa rawat lebih panjang yaitu 4-6 hari (Tyashapsari dan Zulkarnain, 2012; Mehta dan Shrestha, 2018). Pengamatan selama penelitian ditemukan $79 \%$ responden ketika masuk rumah sakit sudah dalam kondisi hipertensi stage 2. Pasien yang masuk rumah sakit dengan tingkat keparahan cukup tinggi memerlukan masa perawatan lebih panjang dibanding datang dengan penyakit sederhana atau stag 1 (Tedja, 2012).

\section{Distribusi Subjek Penelitian}

\section{Berdasarkan Status Malnutrisi}

Tabel 3. Distribusi subjek penelitian berdasarkan status SGA

\begin{tabular}{|c|c|c|c|c|c|c|c|c|}
\hline \multirow{3}{*}{$\begin{array}{c}\text { Stadium } \\
\text { Hipertensi }\end{array}$} & \multicolumn{6}{|c|}{ Status Malnutrisi (SGA) } & \multicolumn{2}{|c|}{ Total } \\
\hline & \multicolumn{2}{|c|}{ Baik } & \multicolumn{2}{|r|}{ Kurang } & \multicolumn{2}{|c|}{ Buruk } & & \\
\hline & $\overline{\mathbf{N}}$ & $\%$ & $\mathbf{N}$ & $\%$ & $\mathbf{N}$ & $\%$ & $\mathbf{N}$ & $\%$ \\
\hline Stage 1 & 2 & 40 & 3 & 40 & 0 & 0 & 5 & 100 \\
\hline Stage 2 & 13 & 68,4 & 4 & 21,1 & 2 & 10,5 & 19 & 100 \\
\hline
\end{tabular}

Berdasarkan tabel 3. Menunjukkan

bahwa pasien hipertensi stage 1 dengan status SGA kurang sebayak 40\%. Sedangkan pasien hipertensi stage 2 yang mengalami status SGA kurang dan buruk berturut-turut sebesar 22,1\% dan 10,5\%. Permasalahan gizi pada pasien di rumah sakit masih sangat kompleks. Salah satunya adalah angka prevalensi malnutrisi dirumah sakit masih cukup tinggi. Hal ini terbukti dari penelitian di tiga rumah sakit yang berbeda dan menyatakan sebanyak $56,9 \%$ pasien menderita malnutrisi saat masuk rumah sakit (Budiningsari dan Hadi, 2004). Kejadian malnutrisi akan berdampak negatif pada pasien, selain mempengaruhi masa rawat yang cukup lama, dampak secara tidak langsung adalah terhadap peningkatan biaya yang dikeluarkan pasien semakin tinggi (Budiningsari dan Hadi, 2004). 


\section{Distribusi Indikator Subjective Global Assessment Pasien}

Subjective global assesmen adalah salah satu alat yang sering digunakan untuk mengetahui status malnutrisi pasien rawat inap di rumah sakit. Alat ini juga lebih sensitif dalam mengetahui lama perawatan pasien.

Tabel 4. Distribusi indikator SGA

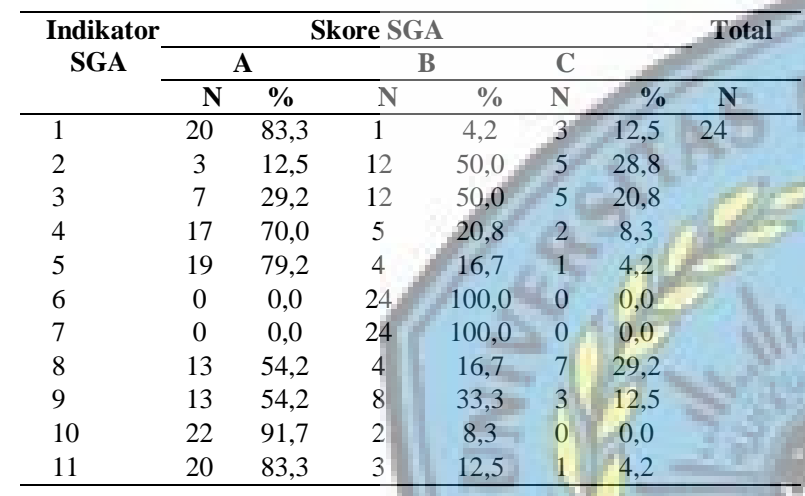

Berdasarkan tabel 4. Skore SGA dikategorikan menjadi 11 indikator, dari indikator tersebut dapat dilihat keseluruhan skore SGA A, B maupun C. Dapat diketahui bahwa indikator ke-satu atau kehilangan berat badan selama 6 bulan terahir skore A lebih dominan 83,3\% dibanding skore B dan C berturut turut $4,2 \%$ dan $12,5 \%$. Artinya bahwa pasien selama 6 bulan terahir tidak mengalami perubahan berat badan atau ada perubahan baik bertambah atau menurun namun masih kurang dari 5\%. Pada indikator ke-2 yaitu perubahan berat badan selama 2 minggu terahir, didapatkan skore A paling sedikit $12,5 \%$ jika dibanding dengan skore B $(50,0 \%)$ dan Skore C $(28,8)$. Hal ini berarti sebagian besar pasien selama 2 minggu terhir mengalami penurunan berat badan, meskipun ada kenaikan tetapi berat badan belum normal atau dibawah berat badan ideal.

Indikator ke-3 adalah perubahan asupan makan sehari-hari dibandingkan dengan kebiasaan. Hasil dari wawancara mendalam sebagian besar pasien mengalami penurunan asupan makan tetapi masih dalam tingkat ringan, terbukti dengan lebih banyak skore B 50,0\% dan C 28\% dibanding skore A $29,2 \%$. Penurunan asupan makan pada pasien meskipun masih tingkat ringan namun tetap menjadi permasalahan yang harus di selesaikan agar kondisi pasien tidak semakin memburuk karena asupan makan sangat penting untuk menunjang pasien dalam kesembuhan (Kasim et al., 2016). Indikator selanjutnya adalah lamanya derajat dari perubahan asupan makan tersebut. Sebanyak 70,0\% adalah skore A, sedangkan skore B dan C berturut-turut 20,8\% dan $8,3 \%$. Walapun terjadi penurunan asupan makan namun perubahan tersebut tidak lebih dari 2 minggu. Perubahan asupan makan terjadi hanya dalam waktu tertentu yaitu saat pasien mengeluhkan adanya gejala-gejala dari hipertensi. 
Indikator ke-5 SGA adalah perubahan gastroitestinal dan didapatkan skore A 79,2\%; skore B 16,7\%; dan skore C $4,2 \%$. Berdasarkan wawancara dengan pasien dan keluarga, banyak ditemukan pasien mengalami penurunan asupan makan, bahkan sampai mual dan muntah namun frekuensi tidak setiap hari dan kurang dari 2 minggu. Pasien akan merasakan gejala tersebut tatkala tekanan darah meningkat yang diikuti dengan pusing dan rasa berat ditungkuk. Indikator ke-6 adalah kapasitas fungsional tubuh pasien. Pada penelitian ini sebagian besar pasien mengalami penurunan aktifitas tahap ringan. Pada umumnya kondisi pasien kompos mentis. Mobilisasi diri hanya dilakukan saat pasien pergi ke kamar mandi dan duduk untuk makan siang. Pada indikator ini sebanyak $100 \%$ pasien berada pada skore $\mathrm{B}$.

\section{Indikator ke-7 yaitu hubungan} penyakit dengan kebutuhan gizi. Penyakit dengan stres metabolik tinggi salah satunya adalah kanker dan ulceratif colitis + diare. Pada penyakit ini akan terjadi katabolisme lebih tinggi, sehingga diperlukan asupan yang adequat untuk dapat menyeimbangkan proses metabolisme dalam tubuh sehingga tidak terjadi penurunan berat badan lebih lanjut (Champe et al., 2010). Pada penelitian ini semua responden adalah pasien dengan diagnosis hipertensi primer sehingga didapat hasil skore B sebanyak $100 \%$ atau stres metabolik tingkat ringan.

Indikator ke-8 dan ke-9 merupakan kehilangan lemak pada subkutan dan massa otot pasien. Setelah diukur dengan skindfod calliper, sebagian besar 54,2\% adalah skore A yang mempunyai arti tidak ada kehilangan pada lemak subkutan pada bagian bisep dan trisep pasien. Sedangkan pada penurunan massa otot juga didapatkan hasil yang sama skore A sebanyak 54,2\%. Pengukuran massa otot dilakukan dibagian tulang selangka, tulang scapula, tulang rusuk dan betis. Indikator ke-10 dan 11 adalah ada atau tidak adanya edama dan asites. Edema adalah penumpukan cairan pada lapisan bawah kulit, biasanya terjadi pada kaki dan tubuh. Sedangakan asites adalah penumpukan cairan khusus yang terjadi pada bagian perut. Kondisi edema dan asites pasien pada penelitian ini semua mengarah pada skore A yaitu berturut turut sebanyak 91,7\% dan $83,3 \%$. Hal ini menandakan bahwa pasien hipertensi hanya sedikit yang didapati menderita edema dan asites. Beberapa pasien saat masuk rumah sakit menderita asites (skore B 12,5\% dan C 4,5\%) namun telah ditangani oleh dokter. Kejadian edema dan 
asites pada penyakit hipertensi dapat terjadi karena adanya ketidak seimbangan antar natrium dan kalium dengan diperantarai adanya proses osmosis dalam sel ketika asupan Na Lebih Tinggi dari pada asupan Kalium sehingga cairan sel akan tertarik keluar dan memenuhi volume darah. Selain meningkatkan curah jantung peningkatan cairan ekstraseluler tersebut juga dapat mengganggu kinerja dari organ ginjal (Murray dkk., 2014). Skore A pada penelitian ini lebih dominan jika dibanding dengan skore yang lainnya. Hal ini menandakan bahwa sebagian besar status malnutrisi pasien dapat dikatan tidak beresiko malnutrisi.

\section{KESIMPULAN DAN SARAN}

\section{Kesimpulan}

Hasil penelitian dan pembahasan dapat disimpulkan sebagai berikut: (1) responden sebagian besar berjenis kelamin perempuan $58,3 \%$. pasien hipertensi lebih banyak diderita oleh kategori usia dewasa sedang yaitu antara umur 51-70 tahun sebanyak 50\%. Tingkat pendidikan responden sebanyak $41,5 \%$ tamatan Sekolah Dasar (SD). Pekerjaan terbanyak sebagai buruh sebesar 41,7\%. Pasien dengan hipertensi stadium 2 yang memiliki lama rawat inap sedang sebanyak 52\%. Sedangkan pasien hipertensi stage 2 yang mempunyai status gizi kurang dan buruk berturut-turut $21,2 \%$ dan $10,5 \%$. Sebagian besar skore SGA pasien adalah $A$ atau tidak malnutrisi.

\section{Saran}

Penilaian status malnutrusi diawal pasien masuk rumah sakit dapat menggunakan metode SGA untuk mendeteksi kejadian resiko malnutrisi. Sedangkan bagi pasien hendaknya selalu memperhatikan status malnutrisi. Selain itu juga agar dapat memanajemen stress yang dapat memicu peningkatan stadium hipertensi.

\section{DAFTAR PUSTAKA}

Agustina, S., Sari, SM., Savita, R. 2014. Faktor Faktor yang Berhubungan Dengan Hipertensi Pada Lansia di Atas Umur 65 Tahun. Jurnal Kesehatan Komunitas. Vol. 2(4): 180-186.

Arini, Desinta. 2016. Hubungan Status Gizi Dan Kepatuhan Diet Rendah Garam Pada Pasien Hipertensi Rawat Inap Di Rumah Sakit PKU Muhammadiyah Surakarta. (Skripsi). Surakarta. Universitas Muhammadiyah Surakarta

Bambungan, Yulinda Margareth Oetari, R., Satibi. 2017. Analisis Biaya Pengobatan Hipertensi Pada Pasien Rawat Inap Di RSUD Sorong. Tunas Tunas Riset Kesehatan. Vol.7(2): 72-76 
Bavelaar, J. W., Otter, C. D., van Bodegraven, ,A.A., Thijs, A., \& van Bokhorst-de van der Schueren,,M.A.E. 2008. Diagnosis and treatment of (disease-related) inhospital malnutrition: The performance of medical and nursing staff. Clinical Nutrition (Edinburgh,Scotland). 27(3): 431-438. doi:http://dx.doi.org/10.1016/j.clnu.20 08.01 .016

Blais, C., Rochette, L., Hamel, D. Dan Poirier, P. 2014. Prevalence, Incidence, Awareness And Control Of Hypertension In The Province Of Quebec: Perspective From Administrative And Survey Data. Canadian Journal Of Public Health. Vol 105(1), Hal: 79-86.

Champe, Pamela C, Harvey Richard A, Ferrier Denise R. 2010. Biokimia Ulasan Bergambar. Edisi.3. Diterjemahkan: Andita Novrianti, dkk. Jakarta. EGC

Dinas Kesehatan Sukoharjo. 2014. Profil Kesehatan Kabupaten Sukoharjo Tahun 2014. Sukoharjo.

Ekawati, A. Dan Afridah, W. 2015. Hubungan Antara Lama Hari Rawat Dengan Antrian Masuk Rumah Sakit Pada Pasien BPJS di Rs. Islam Jemursari Surabaya. Jurnal Ilmiah Kesehatan. 8: 97-103.

Fitria, E. M. N. 2016. Karakteristik Penderita Hipertensi Pada Ulele Kareng Kota Banda Aceh. Sel, 3(2): 64-70.

Guatudde, D., Mutungl, G., Wesonga, R., Kajjura, R., Kasule, H., Muwonge, J., Ssenono, V., Bahendra, SK. 2015. The Epidemiology Of Hypertension In
Uganda: Findings From The National Non-Communicable Diseases Risk Factor Survey. Plos One. Vol 10 (9): 1-13.

Harimawan, A. I. W. Dan Hadi, H. S. 2011. Kajian Metode Subjective Global Assessment (SGA) Dan Nutrition Services Screening Assessment (NSSA) Sebagai Status Gizi Awal Pasien Dewasa Sebagai Prediktor Lama Rawat Inap Dan Status Pulang. Gizi Klinik Indonesia. Vol 7 (3): 99106.

Ismansyah., Ernawati, R., Kusumaastuti, A. 2012. Faktor Faktor yang Berhubungan dengan Lama Hari Rawat Inap Pasien Diabetes Melitus Tipe II. Jurnal Husada Mahakam. Vol3 (4): 144-199.

Kasim, D. A., Harikedua, F. T., Paruntu, O. L. 2016. Asupan Makanan, Status Gizi Dan Lama Hari Rawat Inap Pada Pasien Penyakit Dalam Di Rumah Sakit Advent Manado. GIZIDO. Vol $8(2): 22-34$.

Kementrian Kesehatan. 2013. Riset Kesehatan Dasar 2013.

Lita. 2017. Faktor Resiko Hipertensi di Wilayah Kerja Puskesmas Harapan Raya Pekanbaru. Scientia. Vol 7(2): 159-167.

Nurlindayanti, Eva, Susetyowati, D. 2015. Kecemasan Dan Status Gizi Berhubungan Dengan Lama Rawat Inap Pada Pasien Jantung Di Rsud Jenderal Ahmad. Jurnal Gizi Klinik Indonesia. Vol 3(1): 98-104.

Pakar Gizi Indonesia .2017. Ilmu Gizi Teori Dan Aplikasi. Diedit Oleh I. D. N. S. 
Hardinsyah. Jakarta: Buku Kedokteran EGC.

Peacock, F., Amin, A., Granger, C. B., Pollack, C. V., Levy, P., Nowak, R., Kleinschmidt, K., Varon, J., Wyman, A. Dan Gore, J. M. 2011. Hypertensive Heart Failure: Patient Characteristics, Treatment, And Outcomes. American Journal of Emergency Medicine. Vol 29(8): 855-862.

Price, S.A., Wilson, L.M. 2013. Patofisiologi Konsep Klinis Proses-Proses Penyakit. Edisi VI. Jakarta: EGC.

Ramdhani, R., Respati, T., Irasanti, SN. 2013. Karakteristik dan Gaya Hidup Pasien Hipertensi di Rumah Sakit AlIslam Bandung. Global Medical and Health Communication. Vol 1(2): 63 68

Sedayu, B., Azmi, S., Rahmatini. 2015. Karakteristik Pasien Hipertensi di Bangsal Rawat Inap SMF Penyakit Dalam RSUP DR. M. Djamil Padang Tahun 2013. Jurnal Kesehatan Andalas. Vol 4 (1): 65-69.

Sianaga, E. V., Hiswani,. Jemadi. 2013. Karakteristik Penderita Hipertensi Yang Dirawat Inap Di Rumah Sakit Vita Insani Pematangsiantar Tahun 2010-2011. Gizi, Kesehatan Reproduksi Dan Epidemiologi. Vol 1(2): 1-10.

Silva, H. G. V., Santos, S. O., Silva, N. O., Ribeiro, F. D., Josua, L. L. Dan Moreira, A. S. B. 2012. Nutritional Assessment Associated With Length Of Inpatients ' Hospital Stay," Nutricion Hospitalaria, 27(2): 542547.
Sugiarta, I.G.R.M dan Satriyasa, B. K. 2015. Karakteristik Penderita Hipertensi Yang Dirawat Inap Di Rumah Sakit Umum Pusat Sanglah Tahun 2013. Jurnal Medika Udayana. 4(11)

Sulistyarini, I. 2013. Terapi Relaksasi Untuk Menurunkan Tekanan Darah Dan Meningkatkan Kualitas Hidup Penderita Hipertensi. Jurnal Psikologi. Vol 40(1): 28-38.

Susetyowati. 2014. Penerapan Skrining Gizi Di Rumah Sakit. Yogyakarta: Gajah Mada University Press.

Taniguchi, E, Kawaguchi, $\quad$ T, Itou, M., Oriishi, T, I, Ibi, R, Torii, M., Yoshida, K, , Adachi, Y, Otsuka, M., Uchida, Y, Tanaka, S, Takakura, M. Sata, M. 2011. Subjective global assessment is not sufficient to screen patients with defective hepatic metabolism. Nutrition. Vol 27 (3): 282-286

Tedja, V. R. 2012. Hubungan Antara Faktor Individu, Sosial Demografi, Dan Administrasi Dengan Lama Hari Rawat Pasien Rawat Inap Rumah Sakit Pantai Indah Kapuk Tahun 2011. (Skripsi). Jakarta. Universitas Indonesia.

Triantafyllou, A., Douma, S., Petidis, K., Doumas, M., Panagopoulou, E., Tsotoulidis, S. Dan Zamboulis, C. 2010. Prevalence, Awareness, Treatment And Control Of Hypertension In An Elderly Population In Greece. Journal of Rural And Remote Health Research, Education And Policy. Vol 10(1225): 1-10.

Tyashapsari, M.M.W.E., Zulkarnain, A.K. 
2012. Penggunaan Obat pada Pasien Hipertensi di Instalasi Rawat Inap Rumah Sakit Umum Pusat Dr, Karyadi Semarang. Majalah Farmaseutik. Vol 8(2): 145-151.

Ujung, R.A., Rasmaliah, Jemadi. 2013. Karakteristik Penderita Hipertensi yang Dirawat Inap di Rumah Sakit Umum Daerah Sindikalang Tahun 2010-1012. Gizi, Kesehatan Reproduksi dan Epidemiologi. Vol 2(6): $1-10$

Wakahara, T., Shiraki, M., Murase, K., Fukushima, H., Matsuura, K., Fukao, A., Moriwaki, H. 2007. Nutritional screening with subjective global assessment predicts hospital stay in patients with digestive. Nutrition. Vol 23(9): 634-639

Zizza, C., Herring, A. H., Stevens, J., \& Popkin, B. M. 2004. Length of hospital stays among obese individuals. American Journal of Public Health. Vol 94(9): 1587-91. 